\title{
BMJ Open Evaluation of anticoagulation status for atrial fibrillation on early ischaemic stroke outcomes: a registry-based, prospective cohort study of acute stroke care in Surrey, UK
}

Thang S Han, ${ }^{1,2}$ Christopher H Fry, ${ }^{3}$ David Fluck, ${ }^{4}$ Brendan Affley, ${ }^{5}$ Giosue Gulli, ${ }^{5}$ Christopher Barrett, ${ }^{6}$ Puneet Kakar, ${ }^{7}$ Tasmin Patel, ${ }^{1}$ Sapna Sharma, ${ }^{1}$ Pankaj Sharma ${ }^{1}$

To cite: Han TS, Fry CH, Fluck D, et al. Evaluation of anticoagulation status for atrial fibrillation on early ischaemic stroke outcomes: a registry-based, prospective cohort study of acute stroke care in Surrey, UK. BMJ Open 2017;7:e019122. doi:10.1136/ bmjopen-2017-019122

- Prepublication history for this paper is available online. To view these files, please visit the journal online (http://dx.doi. org/10.1136/bmjopen-2017019122).

Received 14 August 2017 Revised 26 October 2017 Accepted 1 November 2017

CrossMark

For numbered affiliations see end of article.

Correspondence to

Dr Thang S Han;

t.s.han@doctors.org.uk

\section{ABSTRACT}

Objective The relationship of anticoagulation therapies with stroke severity and outcomes have been well documented in the literature. However, none of the previous research has reported the relationship of atrial fibrillation (AF)/anticoagulation therapies with urinary tract infection (UTI), pneumonia and length of stay in hyperacute stroke units (HASUs). The present study aimed to evaluate $\mathrm{AF}$ and anticoagulation status in relation to early outcomes in 1387 men (median age $=75$ years, IQR=65-83) and 1371 women (median age $=83$ years, IQR $=74-89$ ) admitted with acute ischaemic stroke to HASUs in Surrey between 2014 and 2016.

Methods We conducted this registry-based, prospective cohort study using data from the Sentinel Stroke National Audit Programme. Association between AF anticoagulation status with severe stroke on arrival (National Institutes of Health Stroke Scale score $\geq 16$ ), prolonged HASU stay (>3 weeks), UTI and pneumonia within 7 days of admission, severe disability on discharge (modified Rankin Scale score $=4$ and 5 ) and inpatient mortality was assessed by logistic regression, adjusted for age, sex, hypertension, congestive heart failure, diabetes and previous stroke. Results Compared with patients with stroke who are free from $A F$, those with $A F$ without anticoagulation had an increased adjusted risk of having more severe stroke: $5.8 \%$ versus $14.0 \%, 0 \mathrm{R}=2.4(95 \% \mathrm{Cl} 1.6$ to 3.6 , $\mathrm{P}<0.001$ ), prolonged HASU stay: $21.5 \%$ versus $32.0 \%$, $\mathrm{OR}=1.4(1.0-2.0, \mathrm{P}=0.027)$, pneumonia: $8.2 \%$ versus $19.1 \%, 0 R=2.1(1.4-2.9, P<0.001)$, more severe disability: $24.2 \%$ versus $40.4 \%, O R=1.6(1.2-2.1, P=0.004)$ and mortality: $9.3 \%$ versus $21.7 \%, 0 R=1.9(1.4-2.8, P<0.001)$, and $A F$ patients with anticoagulation also had greater risk for having UTI: $8.6 \%$ versus $12.3 \%, \mathrm{OR}=1.9(1.2-3.0$, $\mathrm{P}=0.004)$, pneumonia: $8.2 \%$ versus $11.5 \%, 0 \mathrm{R}=1.6(1.1-$ 2.4, $P=0.025$ ) and mortality: $9.7 \%$ versus $21.7 \%, O R=1.9$ (1.4-2.8, $\mathrm{P}<0.001)$. The median HASU stay for stroke patients with AF without anticoagulation was 10.6 days (IQR=2.8-26.4) compared with 5.8 days $(\mathrm{IQR}=2.3-17.5)$ for those free from $A F(P<0.001)$.

Conclusions Patients with AF, particularly those without anticoagulation, are at increased risk of severe stroke,
Strengths and limitations of this study

- The strengths of the present study include its large homogenous cohort of patients derived from one of the largest National Health Service regions in England.

- The analysis was robustly adjusted for age and sex, as well as major chronic conditions known to associate with stroke including hypertension, congestive heart failure, diabetes and previous stroke.

- The data were collected by healthcare providers for the patients using national Sentinel Stroke National Audit Programme protocol.

- Although data are derived only from Surrey, it is likely to be representative of the rest of the UK as stroke prevalence is similar to that of the UK.

- The study did not collect information on types of oral anticoagulants and international normalised ratio. Information on the duration of anticoagulation treatment for individual patients was also not available, but it is likely to be closely related to their age.

associated with prolonged HASU stay and increased risk of early infection, disability and mortality.

\section{INTRODUCTION}

Each year, about 6.7 million people die of stroke worldwide, accounting for $11.9 \%$ of all deaths. ${ }^{1}$ Stroke results in adverse health consequences including physical disability and cognitive impairment, ${ }^{2-4}$ which imposes enormous burdens on patients, their carers as well as social and healthcare systems. ${ }^{56}$

Patients with existing comorbidities such as diabetes and cardiovascular diseases including coronary heart disease, poorly controlled hypertension or congestive heart failure 
(CHF) have an increased risk of stroke, but atrial fibrillation (AF) remains the biggest risk factor. ${ }^{78}$ Although outcomes for stroke patients have improved significantly in the UK since the introduction of organised hyperacute stroke unit (HASU) care provided by multidisciplinary teams,${ }^{9} 10$ the elderly and those who have chronic health conditions continue to have increased risk of mortality and disability, as well as time to recovery requiring longer stay in hospital after a stroke. ${ }^{11-13}$ The relationship of anticoagulation therapies with stroke severity and outcomes have been well documented in the literature. ${ }^{14-16}$ However, none of the previous research has reported the relationship of $\mathrm{AF} /$ anticoagulation therapies with urinary tract infection (UTI), pneumonia and length of stay in HASU.

The present study aimed to evaluate the relationship of patients with $\mathrm{AF}$ and their anticoagulation status on the severity of stroke on admission, length of stay in HASU, UTI and pneumonia within the first week in hospital, early disability on discharge and inpatient mortality.

\section{METHODS}

\section{Study design, patients and setting}

We conducted this registry-based, prospective cohort study using data from the Sentinel Stroke National Audit Programme (SSNAP), which is the national register of stroke care in England and Wales. Data were collected prospectively from the time of admission up to 6 months after stroke and validated by stroke teams and entered into the SSNAP database via a secure web interface. These data comprise clinical characteristics and care quality of patients admitted to all acute care hospitals in England and Wales with acute ischaemic stroke or primary intracerebral haemorrhage. ${ }^{12}$ We used an anonymised extract of a total of 3309 patients from Surrey, a relatively stable and homogenous population, who were admitted to four HASUs within the county (one of the largest National Health Service (NHS) regions in the England). The hospitals, Ashford and St Peter's ( $\mathrm{n}=1038)$, Frimley Park $(n=1010)$, Royal Surrey County $(n=612)$ and Epsom ( $\mathrm{n}=649)$, were surveyed between January 2014 and February 2016. Twenty-two patients were admitted twice, and two patients were admitted three times. For the purpose of analysis, data from the first admission for these 24 patients who were admitted multiple times were used.

SSNAP has approval from the Confidentiality Advisory Group of the Health Research Authority to collect patient data under section 251 of the NHS Act 2006. No additional ethical approval was sought.

\section{Sociodemographic factors and medical history}

Data were collected for sociodemographic factors including age at arrival, sex and ethnicity, as well as medical history including AF, hypertension, CHF, diabetes mellitus, previous stroke and drug history. In addition, details of new-onset AF cases as well as UTI and pneumonia acquired in hospital within 7 days of admission were documented by the stroke team comprising consultants and stroke nurse specialists, including anticoagulation treatment from the point of admission to discharge.

\section{Diagnosis of stroke and severity}

Stroke was diagnosed based on clinical presentation and brain CT scan as guided by the National Institute for Health and Care Excellence. ${ }^{17}$ The severity of stroke symptoms was assessed by the National Institutes of Health for Stroke Scale (NIHSS) with score range from no symptoms to severe stroke symptoms (NIHSS score $=0$ to 42 ).

\section{Disability and mortality}

Degree of disability or dependence in daily activities were assessed by a modified Rankin Scale (mRS), ranging from no symptoms to severe symptoms ( $\mathrm{mRS}$ score $=0$ to 5$)$ and mortality (mRS score $=6)$.

\section{Categorisation of variables}

Dichotomisation was applied for hypertension, CHF and diabetes according to the presence of history of the condition or not while age was dichotomised at the median value ( $<79$ and $\geq 79$ years). AF and anticoagulation status were categorised into four groups: free from $\mathrm{AF}, \mathrm{AF}$ with anticoagulation, AF without anticoagulation and AF unsuitable for anticoagulation. Severity of stroke and disability were dichotomised into two groups: no symptoms to moderate symptoms (NIHSS score $<16$ and mRS score $<4$ ) and moderately severe to severe (NIHSS score $\geq 16$ and $m R S$ score $=4$ and 5). Prolonged stay in HASU was defined as patients who stayed in a HASU $>3$ weeks (upper fourth quartile of length of stay).

\section{Statistical analysis}

Of the 3309 patients collected in the database, we analysed $2758(83.3 \%)$ patients presented with ischaemic stroke and the remaining $518(15.7 \%)$ patients with haemorrhagic stroke, and $33(1.0 \%)$ patients who were unspecified were excluded. The frequency of patients with AF using anticoagulation before developing an ischaemic stroke was assessed by cross-tabulation and $\chi^{2}$ tests. Most variables had no missing data, which were handled in analysis using a 'listwise deletion of missing data' approach. ${ }^{18}$ Independent t-tests were performed to compare differences between two groups and analysis of variance (ANOVA) between three or more groups, with post hoc analysis where applicable. Multivariable logistic regression was performed to assess the risk of moderately severe to severe stroke on arrival and disability on discharge, inpatient mortality after stroke and prolonged stay in HASU (dependent variables) from comorbidities including AF, hypertension, $\mathrm{CHF}$, diabetes and previous stroke (independent variables). Two logistic regression models were conducted: the first model was unadjusted, and the second was adjusted for age, sex and comorbidities. Analyses were performed using SPSS V.22.0. The null hypothesis was rejected when $\mathrm{P}<0.05$. 
Table 1 Distribution of 2758 patients admitted with acute ischaemic stroke to hospitals in Surrey between January 2014 and February 2016

\begin{tabular}{|c|c|c|}
\hline & Median & IQR \\
\hline Age of men (years) & 75.0 & $65.0-83.0$ \\
\hline \multirow[t]{2}{*}{ Age of women (years) } & 83.0 & $74.0-89.0$ \\
\hline & $\mathbf{n}$ & Proportion (\%) \\
\hline Men:women & $1387: 1371$ & $50.3: 49.7$ \\
\hline $\begin{array}{l}\text { Caucasian: mixed race, } \\
\text { black, Asian and other ethnic } \\
\text { populations: not stated }\end{array}$ & $2544: 180: 34$ & $92.2: 6.6: 1.2$ \\
\hline First stroke: recurrent stroke & 2123:635 & $77.0: 23.0$ \\
\hline AF & 564 & $20.4^{\star}$ \\
\hline AF with anticoagulation & 230 & $40.8+$ \\
\hline AF without anticoagulation & 260 & $46.1 \dagger$ \\
\hline $\begin{array}{l}\text { AF not suitable for } \\
\text { anticoagulation }\end{array}$ & 74 & $13.1 \dagger$ \\
\hline Hypertension & 1446 & 52.4 \\
\hline $\mathrm{CHF}$ & 171 & 6.2 \\
\hline Diabetes & 463 & 16.8 \\
\hline \multicolumn{3}{|l|}{ Stroke severity on arrival } \\
\hline $\begin{array}{l}\text { No stroke symptoms (NIHSS } \\
\text { score: 0) }\end{array}$ & 368 & 13.3 \\
\hline Minor stroke (NIHSS score: 1-4) & 1092 & 39.6 \\
\hline $\begin{array}{l}\text { Moderate stroke (NIHSS score: } \\
5-15)\end{array}$ & 930 & 33.7 \\
\hline $\begin{array}{l}\text { Moderate to severe stroke } \\
\text { (NIHSS score: } 16-20 \text { ) }\end{array}$ & 195 & 7.1 \\
\hline $\begin{array}{l}\text { Severe stroke (NIHSS score: } \\
21-42)\end{array}$ & 173 & 6.3 \\
\hline \multicolumn{3}{|l|}{$\begin{array}{l}\text { Modified Rankin Scale (mRS) on } \\
\text { discharge }\end{array}$} \\
\hline No symptoms (mRS score: 0) & 682 & 24.7 \\
\hline No significant disability (mRS: 1) & 489 & 17.7 \\
\hline Slight disability (mRS score: 2) & 377 & 13.7 \\
\hline $\begin{array}{l}\text { Moderate disability } \\
\text { (mRS score: } 3 \text { ) }\end{array}$ & 362 & 13.1 \\
\hline $\begin{array}{l}\text { Moderately severe disability } \\
\text { (mRS score: } 4 \text { ) }\end{array}$ & 284 & 10.3 \\
\hline Severe disability (mRS score: 5) & 130 & 4.7 \\
\hline Dead (mRS score: 6) & 333 & 12.1 \\
\hline
\end{tabular}

*Proportion relative to the total number of all patients in the present study $(\mathrm{n}=2758)$.

†Proportion relative to the number of patients with $\mathrm{AF}(\mathrm{n}=564)$. $\mathrm{AF}$, atrial fibrillation; $\mathrm{CHF}$, congestive heart failure; $\mathrm{mRS}$, modified Rankin Scale; NIHSS, National Institutes of Health for Stroke Scale.

\section{RESULTS}

Admissions for stroke were almost equally distributed between men $(50.3 \%)$ and women $(49.7 \%)$, with the onset of the first stroke 6.5 years (95\% CI 5.5 to 7.5 , $\mathrm{P}<0.001)$ earlier in men. Table 1 shows that there were $77.0 \%$ of patients presented with first stroke and $23.0 \%$ with recurrent stroke. Most patients were white Caucasians $(92.2 \%)$ with the remaining $6.6 \%$ comprises mixed

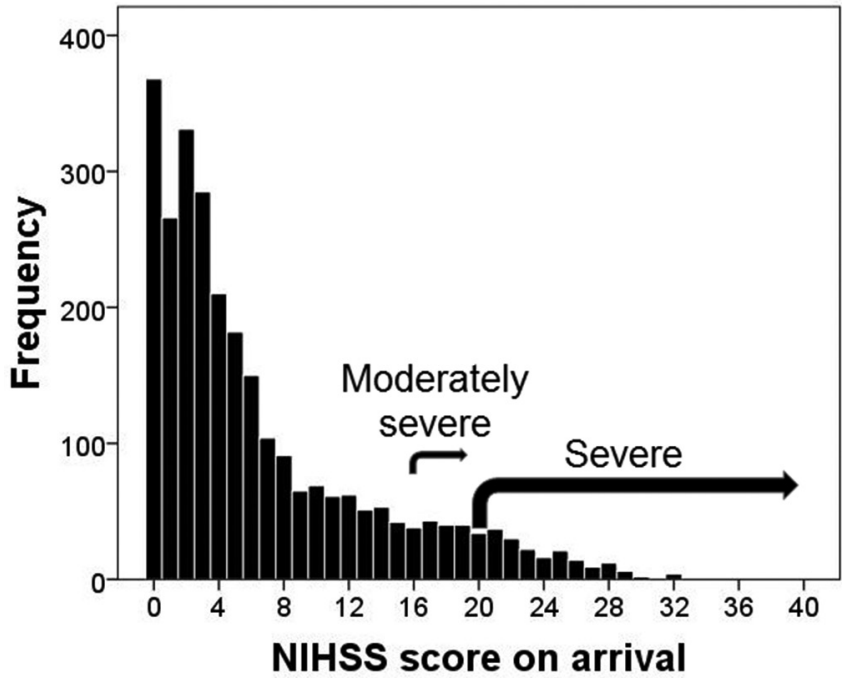

Figure 1 Distribution of patients against severity of stroke on admission based on NIHSS score. NIHSS, National Institutes of Health for Stroke Scale.

race, black, Asian and other ethnic populations and 1.2\% not stated. On arrival, $546(20.4 \%)$ patients had a history of $\mathrm{AF}$, in whom $40.8 \%$ were treated in the community with an anticoagulant, while $46.1 \%$ were untreated, although $13.1 \%$ had been considered for anticoagulation and deemed unsuitable by their healthcare providers. Also on arrival, $7.1 \%$ of patients had moderate to severe stroke symptoms (NIHSS score $=16-20$ ) and $6.3 \%$ had severe symptoms (NIHSS=21-42). The remainder had no symptoms $(13.3 \%$, NIHSS $=0)$, minor $(39.6 \%$, NIHSS $=1-4)$ or moderate $(33.7 \%$, NIHSS $=5-15)$ symptoms; a more detailed analysis of NIHSS scores is shown in figure 1. On discharge, $10.3 \%$ and $4.7 \%$ of the original patients, respectively, had moderately severe $(\mathrm{mRS}$ score $=4)$ or severe (mRS score $=5$ ) symptoms. The rate of inpatient mortality was $12.1 \%$ (table 1 ).

Baseline characteristics of patients in different categories of $\mathrm{AF}$ and anticoagulation status are shown in table 2. The median age of patients without AF were 77 years old, while those with $\mathrm{AF}$ were between 83 and 84 years old. Hypertension, $\mathrm{CHF}$ and moderate to severe stroke were more commonly observed among patients with $\mathrm{AF}$ than those free of AF.

Patients free from AF had significantly less severe stroke on admission as reflected by a lower NIHSS score $(F=21.8$, $\mathrm{P}<0.001)$ and disability on discharge as indicated by a lower mRS score $(F=20.9, \mathrm{P}<0.001)$ than patients with $\mathrm{AF}$ of any anticoagulation status (with anticoagulation, without anticoagulation or unsuitable for anticoagulation in the community) (figure 2). ANOVA with post hoc analysis by least significant difference tests showed that NIHSS score on arrival (figure 2A) and $\mathrm{mRS}$ on discharge (figure 2B) were significantly lower $(\mathrm{P}<0.01)$ for those free from $\mathrm{AF}$ compared with any of the other three groups of patients with AF (with anticoagulation, without anticoagulation or unsuitable for anticoagulation). The NIHSS score for those with $\mathrm{AF}$ who were treated with anticoagulant was 
Table 2 Baseline characteristics of patients admitted with ischaemic stroke according the AF and anticoagulation status

\begin{tabular}{|c|c|c|c|c|c|c|c|c|}
\hline & \multicolumn{2}{|l|}{$\begin{array}{l}\text { Non-AF } \\
(n=2194)\end{array}$} & \multicolumn{2}{|c|}{$\begin{array}{l}\text { AF with anticoagulation } \\
(\mathrm{n}=230)\end{array}$} & \multicolumn{2}{|c|}{$\begin{array}{l}\text { AF without } \\
\text { anticoagulation } \\
(n=260)\end{array}$} & \multicolumn{2}{|c|}{$\begin{array}{l}\text { AF not suitable for } \\
\text { anticoagulation } \\
(n=74)\end{array}$} \\
\hline & Median & IQR & Median & IQR & Median & IQR & Median & IQR \\
\hline Age (years) & 77.0 & $66.0-85.0$ & 83.0 & $77.0-88.0$ & 84.0 & $77.0-90.0$ & 84.0 & $78.8-88.2$ \\
\hline & $\mathbf{n}$ & $\%$ & $\mathbf{n}$ & $\%$ & $\mathbf{n}$ & $\%$ & $\mathbf{n}$ & $\%$ \\
\hline Men:women & 1133:1061 & $51.6: 48.4$ & $111: 119$ & 48.3:51.7 & $106: 154$ & 40.8:59.2 & $37: 37$ & 50.0:50.0 \\
\hline $\mathrm{CHF}$ & 105 & 4.8 & 28 & 12.2 & 10 & 13.5 & 171 & 6.2 \\
\hline Diabetes & 364 & 16.6 & 44 & 19.1 & 41 & 15.8 & 14 & 18.9 \\
\hline $\begin{array}{l}\text { Moderate to severe } \\
\text { stroke on arrival } \\
\text { (NIHSS score: } \geq 16 \text { ) }\end{array}$ & 114 & 5.2 & 17 & 7.4 & 36 & 13.8 & 6 & 8.1 \\
\hline
\end{tabular}

AF, atrial fibrillation; CHF, congestive heart failure; NIHSS, National Institutes of Health for Stroke Scale.

also lower than that of those with $\mathrm{AF}$ who were not treated with $(\mathrm{P}=0.011)$ or considered unsuitable for anticoagulation $(\mathrm{P}=0.023)$.

Table 3 shows that compared with patients with stroke who were free of AF, those with AF but not anticoagulated had an increased adjusted risk of having more severe stroke: $5.8 \%$ versus $14.0 \%$, OR=2.4 $(95 \%$ CI 1.6 to $3.6, \mathrm{P}<0.001)$, prolonged HASU stay: $21.5 \%$ versus $32.0 \%, \mathrm{OR}=1.4 \quad(95 \%$ CI 1.0 to $2.0, \mathrm{P}=0.027)$, pneumonia: $8.2 \%$ versus $19.1 \%$, OR=2.1 (95\% CI 1.4 to 2.9 , $\mathrm{P}<0.001$ ), more severe disability: $24.2 \%$ versus $40.4 \%$, $\mathrm{OR}=1.6(95 \% \mathrm{CI} 1.2$ to $2.1, \mathrm{P}=0.004)$ and mortality: $9.3 \%$ versus $21.7 \%$, OR $=1.9$ (95\% CI 1.4 to $2.8, \mathrm{P}<0.001$ ). Patients with AF with anticoagulation also had greater risk than those free of AF for having UTI: $8.6 \%$ versus
$12.3 \%, \mathrm{OR}=1.9$ (95\% CI 1.2 to $3.0, \mathrm{P}=0.004)$, pneumonia: $8.2 \%$ versus $11.5 \%, \mathrm{OR}=1.6(95 \% \mathrm{CI} 1.1$ to $2.4, \mathrm{P}=0.025)$ and mortality: $9.7 \%$ versus $21.7 \%$, OR=1.9 (95\% CI 1.4 to $2.8, \mathrm{P}<0.001)$.

The median length of stay in HASU of 5.8 days (IQR=2.3-17.5 days) for patients with stroke who were free of AF. In comparison, the corresponding values were 10.6 days $(\mathrm{IQR}=2.8-26.4$ days $)$ for patients with stroke with $\mathrm{AF}$ without anticoagulant $(\mathrm{P}<0.001)$ and 9.8 days (IQR=4.0-30.0 days) for stroke patients who were deemed unsuitable for anticoagulation $(\mathrm{P}=0.010)$, while anticoagulation in patients with $\mathrm{AF}$ reduced the median length of stay in HASU to 7.1 days ( $\mathrm{IQR}=3.1-19.3$ days), which is not significantly different from patients with stroke who are free of $\mathrm{AF}(\mathrm{P}=0.062)$.

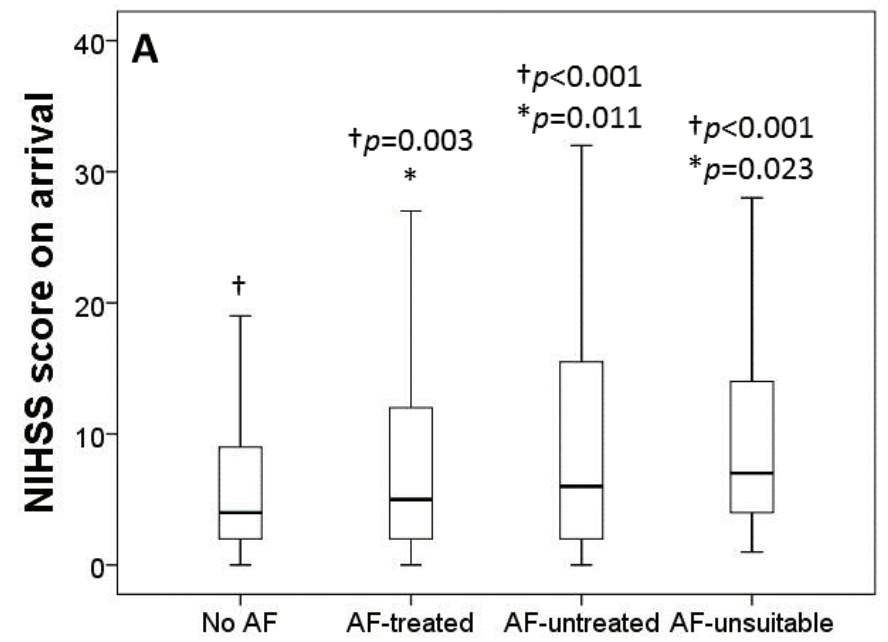

$A F$ and anticoagulation status

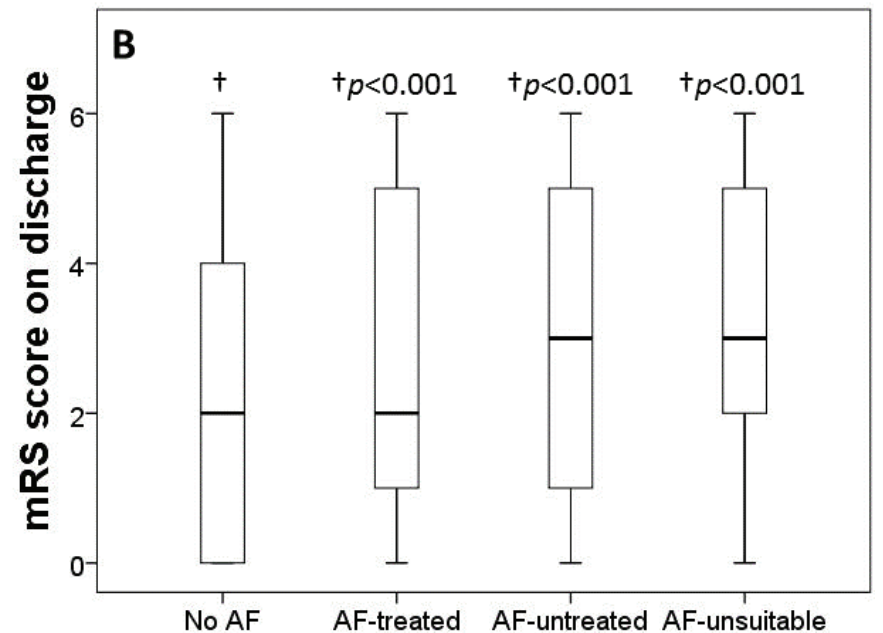

$A F$ and anticoagulation status

Figure 2 Box plots showing AF and anticoagulation status in relation to stroke severity on arrival indicated by NIHSS score (A) and severity of disability on discharge indicated by mRS score (B). ANOVA showed significant group differences $(P<0.001)$, therefore post hoc least significant difference tests were performed to compare NIHSS score between those ${ }^{\dagger}$ free from AF (no AF) and other three AF groups of different anticoagulation status, and between *AF with anticoagulation (AF-treated) and AF without anticoagulation (AF-untreated) groups. Box plots represent median and IQR; whiskers represent the 5th and 95th percentiles. AF, atrial fibrillation; ANOVA, analysis of variance; mRS, modified Rankin Scale; NIHSS, National Institutes of Health for Stroke Scale. 


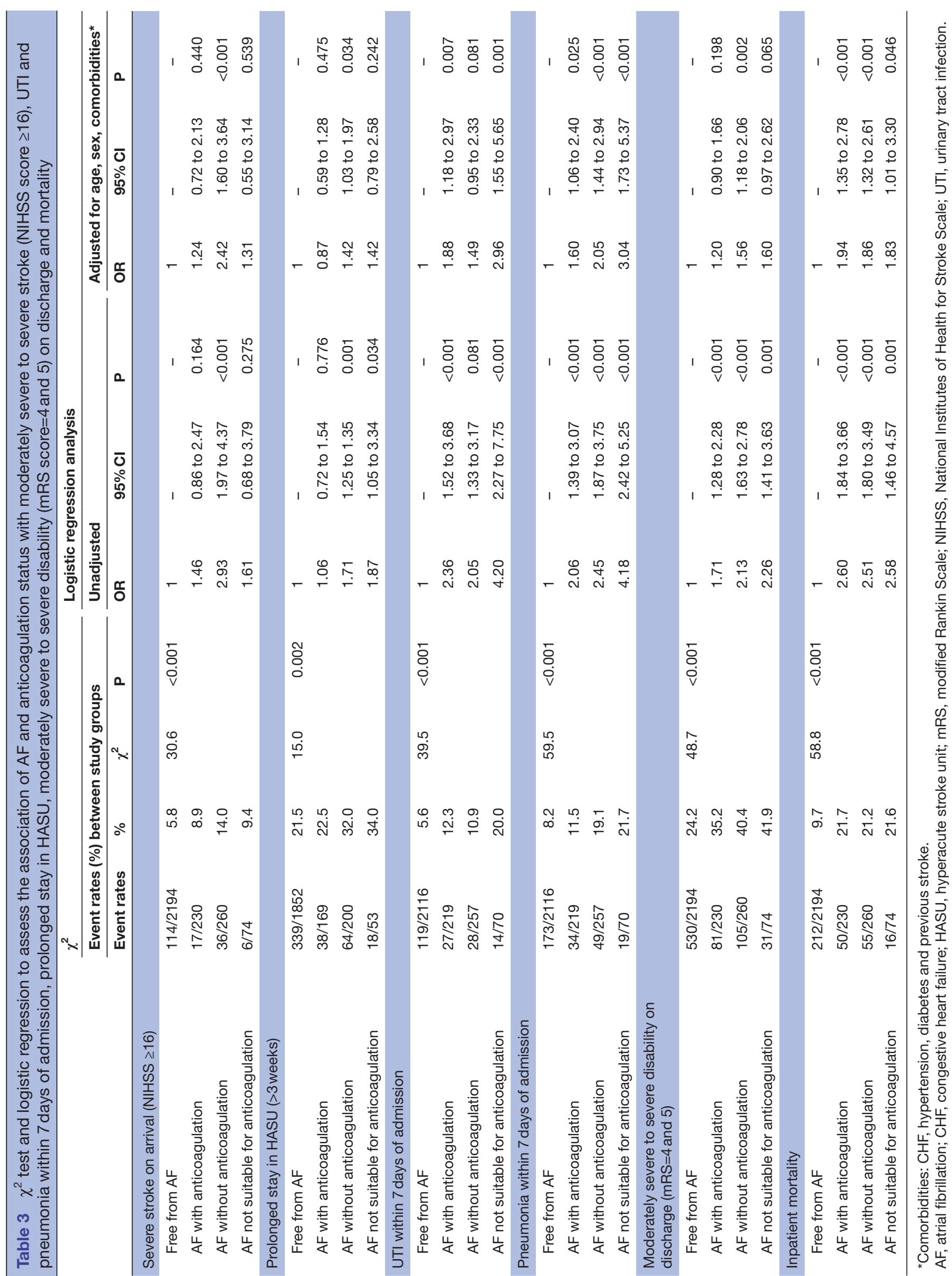


Among patients with AF who were not anticoagulated or deemed unsuitable for anticoagulation on admission, $91.8 \%$ and $75.0 \%$ of these patients, respectively, were treated with an anticoagulant on discharge $\left(\chi^{2}=16.2\right.$, $\mathrm{P}<0.001)$.

\section{DISCUSSION}

We show that compared with patients without a history of $\mathrm{AF}$, those with $\mathrm{AF}$ without anticoagulation had a greater risk of severe stroke (NIHSS score $\geq 16$ ), prolonged stay in HASU ( $>3$ weeks), risk of early pneumonia, more severe disability on discharge ( $\mathrm{mRS}$ score $=4$ and 5 ) and inpatient mortality by 1.4 -fold to 2.4 -fold. Our study of the association of AF/anticoagulation therapies with pneumonia, UTI and length of stay in HASU is novel. It is notable that patients with $\mathrm{AF}$ who were anticoagulated had a reduced risk of severe stroke and length of stay in a HASU to the same level as those who were free from AF. The increased risk of severe stroke on arrival, prolonged stay in HASU, more severe disability on discharge and inpatient mortality in patients with $\mathrm{AF}$ without anticoagulation was independent of age, sex, hypertension, CHF, diabetes and previous stroke.

Given the growing ageing population, ${ }^{19}$ disability from stroke will continue to impose massive burdens on healthcare systems in the foreseeable future worldwide, including the UK. There is therefore a need for early identification of $\mathrm{AF}$, the biggest treatable risk factor of stroke, through systematic screening of at-risk patients in the community and intensive treatment for those diagnosed with $\mathrm{AF}^{20}{ }^{20}$ However, there is evidence of undertreatment of AF in the community. In the present study, we observed $46.1 \%$ of patients with AF who were not on anticoagulation on admission. This figure is consistent with findings from Bassand et $a l^{21}{ }^{21}$ who observed that $36.9 \%$ of $\mathrm{AF}$ patients with $\mathrm{CHA}_{2} \mathrm{DS}_{2}-\mathrm{VASc} \geq 2$ were not on anticoagulant therapy at inclusion and from Perez et al, who found that only $50 \%$ of patients with AF who were eligible for anticoagulation were given this treatment. ${ }^{22}$ Similarly, Waldo et al studied 945 patients and found that of the $86 \%$ of patients who were at high risk of stroke, only $55 \%$ received warfarin. ${ }^{23}$ Data from our study revealed that most patients with $\mathrm{AF}$ who were not treated or deemed unsuitable for treatment with an anticoagulant on admission were subsequently treated on discharge. This suggests that the number of patients who are actually contraindicated to anticoagulation is small, with most being simply untreated.

Greater collaboration between primary care and specialist cardiology services is necessary to improve stroke prevention through appropriate treatment of AF. The roles of experts such as cardiologists, neurologists and haematologists are vital in providing specialist advice on anticoagulation therapy for patients who pose as a treatment dilemma for anticoagulation, such as those with a history of bleeding. Other preventable risk factors such as obesity, hypertension, dyslipidaemia and hyperglycaemia/insulin resistance ${ }^{202425}$ should also be managed intensively.

A number of important findings emerge from the present study. All patients with AF, whether treated or untreated with an anticoagulant, have increased risks of early hospital-acquired infections, disability and mortality. This suggests the inherent risk of AF that may be associated with other causes of cardiovascular disease leads to worse outcomes of stroke. ${ }^{26}$ In the present study, we observed that there was no greater risk for having more severe stroke or prolonged stay in HASU among stroke patients with $\mathrm{AF}$ who were anticoagulated than that of those who were free of $\mathrm{AF}$; this evidence reinforces the value of intensive treatment of $\mathrm{AF}$ with anticoagulants. ${ }^{14}$

The strengths of the present study include its large homogenous cohort of patients derived from one of the largest NHS regions in England. The analysis was robustly adjusted for age and sex, as well as major chronic conditions known to associate with stroke including hypertension, CHF, diabetes, previous stroke and in particular stroke subtype. The data were collected by healthcare providers for the patients using national SSNAP protocol. Our study focused on early disability on discharge and inpatient mortality. It would be of interest to assess the impact of AF anticoagulation status on these outcomes in longer term. Although data are derived only from Surrey, it is likely to be representative of the rest of the UK as stroke prevalence is similar to that of the UK. ${ }^{12}$ Our study did not collect information on types of oral anticoagulants or INR that could have some bearing on the outcomes. This information is beyond the scope of our study. The length of anticoagulation treatment for individual patients was not available, but it is likely that it is closely related to their age. We chose cut-off point for NIHSS score at 16 based on previous studies showing that a baseline score of $\geq 16$ (moderately severe to severe stroke) was a strong predictor of mortality or severe disability, ${ }^{27}$ while cut-off point for $\mathrm{mRS}$ score at 4 indicates that, beyond this point, functional disability begins to worsen due to increasing severity of stroke. ${ }^{28}$ 'Prolonged stay' has variably been described. ${ }^{29}$ In the present study, we defined prolonged stay for those who stayed in HASU $>3$ weeks as this point reflects the upper quartile of length of stay in HASU. It should be emphasised that these cut-off points tend to be arbitrary and the higher the level, the more severe is the condition. We have explored various other levels including cut-off points for NIHSS score at 12, mRS score at 3 and length of stay in HASU at 1 week (50th centile), all showing similar patterns of, but weaker, association with $\mathrm{AF}$ treatment status.

In conclusion, patients with $\mathrm{AF}$, particularly those without anticoagulation, are at increased risk of severe stroke, associated with prolonged HASU stay and increased risk of early infection, disability and mortality.

\section{Author affiliations}

${ }^{1}$ Institute of Cardiovascular Research, Royal Holloway, University of London, Egham, UK 
${ }^{2}$ Department of Endocrinology, Ashfordand St Peter's NHS Foundation Trust, Chertsey, UK

${ }^{3}$ School of Physiology, Pharmacology and Neuroscience, University of Bristol, Bristol, UK

${ }^{4}$ Department of Cardiology, Ashford and St Peter's NHS Foundation Trust, Chertsey, UK

${ }^{5}$ Department of Stroke, Ashford and St Peter's NHS Foundation Trust, Chertsey, UK

${ }^{6}$ Department of Stroke, NHS Frimley Health Foundation Trust, Frimley, UK

${ }^{7}$ Department of Stroke, Epsom and St Helier University Hospitals, Epsom, UK

Acknowledgements The authors wish to thank the patients and all those who were involved in the surveys in the study and Adrian Blight (currently at Department of Stroke, St George's University Hospitals NHS Foundation Trust) for his contribution towards data collection from Royal Surrey County Hospital Foundation Trust.

Contributors TSH and PS reviewed the topic-related literature. BA, GG, CB, PK and TP performed the study coordination and data collection. TSH and PS performed the study concept and analysis design. TSH wrote the first draft, analysed and interpreted the data and revised the manuscript. CHF, DF, SS and PS edited the manuscript. All authors checked, interpreted results and approved the final version. TSH and PS are the guarantors for the study.

Competing interests None declared.

Provenance and peer review Not commissioned; externally peer reviewed.

Data sharing statement № additional data are available.

Open Access This is an Open Access article distributed in accordance with the Creative Commons Attribution Non Commercial (CC BY-NC 4.0) license, which permits others to distribute, remix, adapt, build upon this work non-commercially, and license their derivative works on different terms, provided the original work is properly cited and the use is non-commercial. See: http://creativecommons.org/ licenses/by-nc/4.0/

(C) Article author(s) (or their employer(s) unless otherwise stated in the text of the article) 2017. All rights reserved. No commercial use is permitted unless otherwise expressly granted.

\section{REFERENCES}

1. World Health Organisation www.who.int/mediacentre/factsheets/ fs310/en/.

2. Lin HJ, Wolf PA, Kelly-Hayes M, et al. Stroke severity in atrial fibrillation. The Framingham Study. Stroke 1996;27:1760-4.

3. Lamassa M, Di Carlo A, Pracucci G, et al. Characteristics, outcome, and care of stroke associated with atrial fibrillation in Europe: data from a multicenter multinational hospital-based registry (The European Community Stroke Project). Stroke 2001;32:392-8.

4. Crichton SL, Bray BD, McKevitt C, et al. Patient outcomes up to 15 years after stroke: survival, disability, quality of life, cognition and mental health. J Neurol Neurosurg Psychiatry 2016;87:1091-8.

5. Youman P, Wilson K, Harraf F, et al. The economic burden of stroke in the United Kingdom. Pharmacoeconomics 2003;21(Suppl 1):43-50.

6. Saka O, McGuire A, Wolfe C. Cost of stroke in the United Kingdom. Age Ageing 2009;38:27-32.

7. Wolf PA, Abbott RD, Kannel WB. Atrial fibrillation as an independent risk factor for stroke: the Framingham Study. Stroke 1991;22:983-8.

8. Anon. Risk factors for stroke and efficacy of antithrombotic therapy in atrial fibrillation. Analysis of pooled data from five randomized controlled trials. Arch Intern Med 1994;154:1449-57.

9. Stroke Unit Trialists' Collaboration. Organised inpatient (stroke unit) care for stroke. Cochrane Database Syst Rev 2007;4:CD000197.
10. Turner M, Barber M, Dodds $\mathrm{H}$, et al. The impact of stroke unit care on outcome in a Scottish stroke population, taking into account case mix and selection bias. J Neurol Neurosurg Psychiatry 2015;86:314-8.

11. Maeshima S, Osawa A, Hayashi T, et al. Elderly age, bilateral lesions, and severe neurological deficit are correlated with stroke-associated pneumonia. J Stroke Cerebrovasc Dis 2014;23:484-9.

12. Royal College of Physicians, Clinical Effectiveness and Evaluation Unit on behalf of the Intercollegiate Stroke Working Party. Based on stroke patients admitted to and/or discharged from hospital between January - March 2016: Royal College of Physicians, Clinical Effectiveness and Evaluation Unit on behalf of the Intercollegiate Stroke Working Party, 2016.

13. Tam AKH, Bayley MT. A narrative review of the impact of medical comorbidities on stroke rehabilitation outcomes. Disabil Rehabil 2017:4:1-7

14. Hylek EM, Go AS, Chang Y, et al. Effect of intensity of oral anticoagulation on stroke severity and mortality in atrial fibrillation. N Engl J Med 2003;349:1019-26.

15. O'Donnell M, Oczkowski W, Fang J, et al. Preadmission antithrombotic treatment and stroke severity in patients with atrial fibrillation and acute ischaemic stroke: an observational study. Lancet Neurol 2006;5:749-54.

16. Xian Y, O'Brien EC, Liang L, et al. Association of preceding antithrombotic treatment with acute ischemic stroke severity and in-hospital outcomes among patients with atrial fibrillation. JAMA 2017;317:1057-67.

17. National Institute for Health and Care Excellence. Atrial fibrillation: the management of atrial fibrillation. London: National Institute for Health and Care Excellence, 2014.

18. Acock AC. Working with missing values. J Marriage Fam 2005;67:1012-28.

19. World Health Organization. "World report on ageing and health". Geneva: World Health Organization, 2015.

20. Feigin VL, Roth GA, Naghavi M, et al. Global burden of stroke and risk factors in 188 countries, during 1990-2013: a systematic analysis for the global burden of disease study 2013. Lancet Neurol 2016;15:913-24.

21. Bassand JP, Accetta G, Camm AJ, et al. Two-year outcomes of patients with newly diagnosed atrial fibrillation: results from GARFIELD-AF. Eur Heart J 2016;37:2882-9.

22. Perez I, Melbourn A, Kalra L. Use of antithrombotic measures for stroke prevention in atrial fibrillation. Heart 1999;82:570-4.

23. Waldo AL, Becker RC, Tapson VF, et al. Hospitalized patients with atrial fibrillation and a high risk of stroke are not being provided with adequate anticoagulation. J Am Coll Cardiol 2005;46:1729-36.

24. Weir CJ, Murray GD, Dyker AG, et al. Is hyperglycaemia an independent predictor of poor outcome after acute stroke? Results of a long-term follow up study. BMJ 1997;314:1303-6.

25. Milionis HJ, Rizos E, Goudevenos J, et al. Components of the metabolic syndrome and risk for first-ever acute ischemic nonembolic stroke in elderly subjects. Stroke 2005;36:1372-6.

26. Kamel H, Okin PM, Elkind MS, et al. Atrial fibrillation and mechanisms of stroke: time for a new model. Stroke 2016;47:895-900.

27. Adams HP, Bendixen BH, Leira E, et al. Antithrombotic treatment of ischemic stroke among patients with occlusion or severe stenosis of the internal carotid artery: a report of the Trial of Org 10172 in Acute Stroke Treatment (TOAST). Neurology 1999;53:122-5.

28. Fernandez A, Schmidt JM, Claassen J, et al. Fever after subarachnoid hemorrhage: risk factors and impact on outcome. Neurology 2007;68:1013-9.

29. Stein M, Misselwitz B, Hamann GF, et al. Defining prolonged length of acute care stay for surgically and conservatively treated patients with spontaneous intracerebral hemorrhage: a population-based analysis. Biomed Res Int 2016;2016:1-6. 